\section{Santa María de los Arcos de Tricio (La Rioja), Santa Coloma (La Rioja) y La Asunción de San Vicente del Valle (Burgos). Tres miembros de una familia arquitectónica}

Luis Caballero, Fernando ArCe, M. a de los Ángeles Utrero Unidad Asociada CSIC/Universidad del País Vasco. Grupo de Arqueología Tardoantigua y Medieval. Arqueología de la Arquitectura (GATMAA)

\section{Resumen}

Existe una serie de edificios altomedievales repartidos por las actuales provincias de Álava, Burgos y La Rioja que forman una familia arquitectónica cuyos principales rasgos de parentesco son la cubrición de los espacios absidales con cúpulas en piedra toba apeadas en pechinas y la recurrente reutilización de sillería procedente de fábricas romanas. La adscripción cronológica de los diferentes componentes de esta familia edilicia es

sorprendentemente variada. Algunos de ellos son tenidos como obras genuinamente romanas mientras que otros se fechan en época visigoda o incluso más allá. Pensamos que esta disparidad cronológica es históricamente incomprensible. La homogeneidad en las técnicas y resultados tiene que responder a un horizonte cronológico/material igualmente homogéneo que difícilmente puede durar tantos siglos. Nosotros defendemos unas fechas altomedievales (siglos IX-X) para todos los integrantes de este grupo arquitectónico, tanto por razones técnicas como históricas.

Palabras clave: Reutilización; cúpulas; pechinas; altomedieval

\section{Abstract}

There is a series of high medieval buildings scattered around the present-day provinces of Álava, Burgos and La Rioja which form an architectonic family whose main common features are the covering of the apsidal spaces with travertine stone domes propped up on squinches and the recurrent reuse of masonry from Roman stone. The chronological ascription of the different components of this family of buildings is surprisingly varied. Some are held as genuine Roman works while others are dated in the Visigoth period or even later. We believe that this chronological disparateness is historically incomprehensible. The homogeneity of techniques and results must correspond to an equally homogenous

chronological/material period which is unlikely to last for so many centuries. We defend high medieval dates (9th-10th century) for all the members of this architectonic group, both for technical and historic reasons.

Key words: Reuse; domes; squinches; high medieval.

\section{UNA FAMILIA ARQUITECTÓNICA}

Santa María de los Arcos de Tricio, Santa Coloma y La Asunción de San Vicente del Valle forman parte de un grupo de edificios altomedievales (figura 1) definido por el uso recurrente de sillería romana reutilizada, la presencia de bóvedas de piedra toba sobre pechinas cubriendo los ábsides y una dispersión geográfica colindante: Álava (San Román de Tobillas), el occidente riojano (Coloma, Tricio, Ventas Blancas) y el área nororiental burgalesa (La Asunción, San Felices de Oca, San Pedro de Arlanza, Santa Cecilia de Barriosuso y Quintanilla de las Viñas). Hay, no obstante, un ejemplo perteneciente al grupo, Hérmedes del Cerrato $(\mathrm{Pa}-$ lencia), que se encuentra fuera de este ámbito territorial.

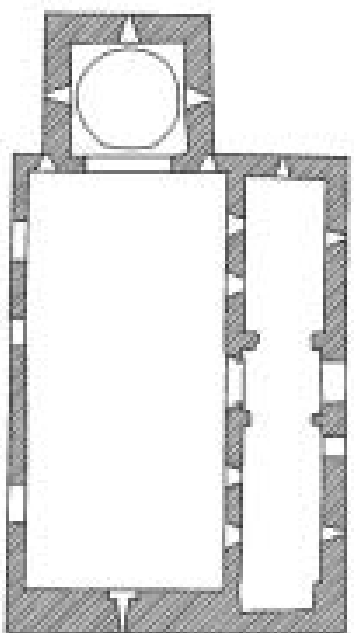

SAN VICENTE DEL VALIE
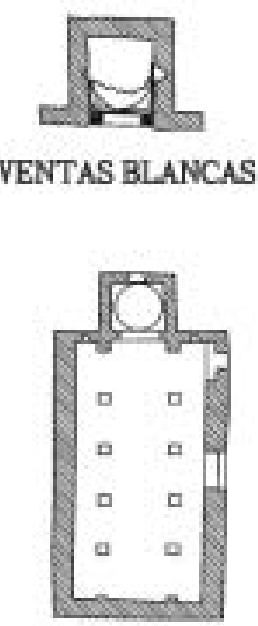

SAN PEDRO DE ARLANZA

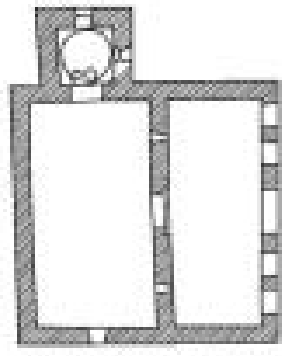

BARRIOSUSO

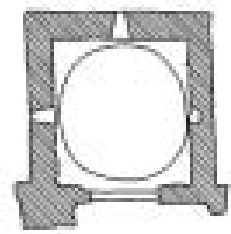

SAN FELICES DE OCA

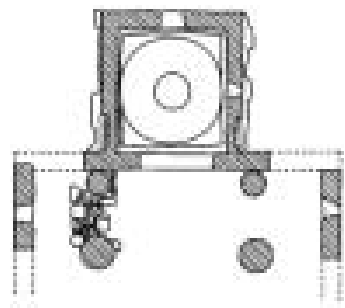

TRICIO

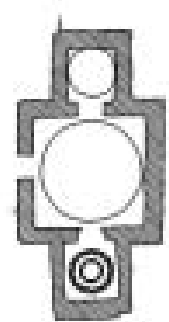

SANTA COLOMA

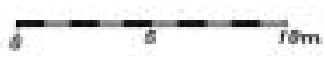

Fig. 1. Planta de las iglesias del grupo castellano-riojano 
Los edificios que forman esta familia arquitectónica cuentan con propuestas cronológicas diversas que van desde el siglo VII al siglo X: Quintanilla es fechada por la mayoría de autores en el siglo VII pero otros apuestan por el VIII o el IX; Tricio y Coloma en el VII y en el IX-X aunque con partes originales romanas; San Vicente del Valle en diferentes fases que irían desde el siglo VI al IX; Ventas Blancas en el VII; Tobillas con dos momentos altomedievales en los siglos IX y X; Santa Cecilia en el IX; San Felices de Oca en el viI.

Prácticamente todas las adscripciones temporales se basan en criterios estilísticos. A excepción de San Román de Tobillas, que cuenta con una huella documental y epigráfica, el resto carece de evidencias textuales que puedan relacionarse con los momentos fundacionales. Tampoco la arqueología, allí donde se ha excavado, ha servido para despejar incertidumbres cronológicas salvo, de nuevo, el caso de Tobillas (AzKARATE, 1996). Las excavaciones en Quintanilla, Ventas Blancas, Tricio, Oca o San Vicente del Valle ni confirman ni desmienten cualquiera de las propuestas posibles si bien, como es natural, cada autor proponga tal o cual fecha. Normalmente se tiende a datar el subsuelo de forma apriorística dependiendo de la idea previa que tenga cada excavador. Si se piensa que la iglesia es, por ejemplo, del siglo VII será «obvio» que los niveles fundacionales, cuando se encuentren, serán tenidos del mismo momento. La aplicación, por nuestra parte, de la llamada arqueología de la arquitectura en una serie de edificios englobados en esta familia arquitectónica no viene ni a suplir a la arqueología excavatoria ni a pretender solucionar por sí sola los problemas cronológicos. Esto sólo se podría conseguir, y no necesariamente siempre, con un análisis arqueológico integral (excavación de subsuelo y cubiertas, lectura de paramentos) unido a un vaciado documental exhaustivo y la aplicación, si hay ocasión, de analíticas experimentales (C14, dendrocronología, termoluminiscencia). Lo que ofrecen las lecturas son secuencias relativas que permiten conocer en profundidad la historia constructiva/destructiva de los edificios, casi siempre mucho más rica y compleja de lo que se piensa. La fase o fases altomedievales detectadas en cada caso estarán definidas por unas características técnicas y constructivas que le son propias cuyo conocimiento y sistematización han de sentar las bases de unas tipologías arqueológicas más fiables que las todavía muy presentes y utilizadas tipologías "estilísticas» de una Historia del Arte no muy atenta por ahora a los descubrimientos aportados por los análisis estratigráficos que permiten, entre otras cosas, no caer en los habituales sincronismos.

La presencia historiográfica de las tres iglesias de las que vamos a hablar es más bien escasa. Santa Coloma y Tri-

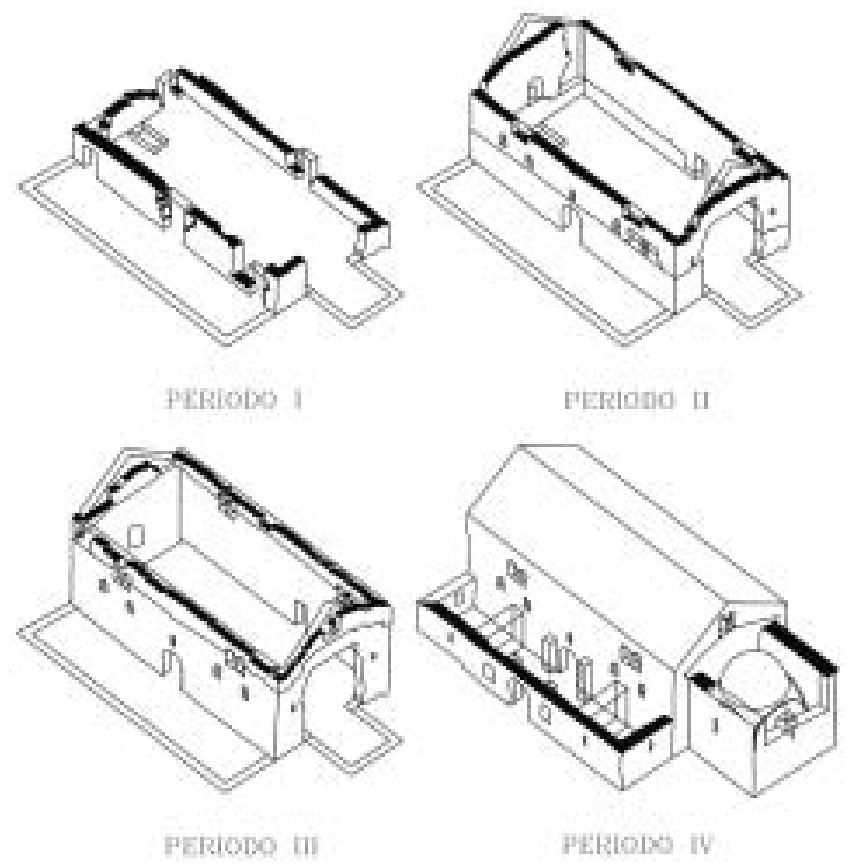

Fig. 2. Reconstrucción de las etapas altomedievales de la Asunción

cio (Uranga e ÍñIguez, 1971; Andrés, 1982; Heras, 1986) se explican desde hace algunos años como iglesias surgidas en época visigoda a partir de la adecuación al culto cristiano de antiguos mausoleos romanos: el actual ábside en Tricio y el cuerpo central en Santa Coloma. La Asunción también se supone una iglesia que surge de una fábrica anterior, en este caso un edificio residencial levantado en época visigoda (APARICIO y DE LA FUENTE, 1996).

\section{LAS CUATRO IGLESIAS DE LA ASUNCIÓN}

Este edificio burgalés arroja una rica secuencia de intervenciones prerrománicas, cuatro en total (figura 2). Las tres primeras, documentadas en los alzados del aula, tienen en común el reempleo de sillares romanos, mientras que la cuarta, perteneciente al ábside y pórtico meridional, se realiza con mampostería de lajas y cubre el espacio presbiterial con una cúpula sobre pechinas en piedra toba. Las dos primeras fases de sillería parecen muy cercanas en el tiempo ya que se observa la aplicación de unos recursos que dan resultados semejantes. De hecho, la discriminación vino dada por pequeños detalles como la forma y ubicación de los mechinales, siendo prácticamente indiferenciables en aspectos como las tallas y la puesta en obra de los sillares reutilizados. La tercera, aunque también en sillería reutilizada, responde a una forma de trabajo con peores resultados tanto en el trabajo de la piedra como en su asiento en la fábrica. A esta fase se adscriben unos interesantes capiteles de mármol ubicados en los parteluces de las ventanas geminadas superiores. La cuarta emplea un aparejo totalmente dis- 


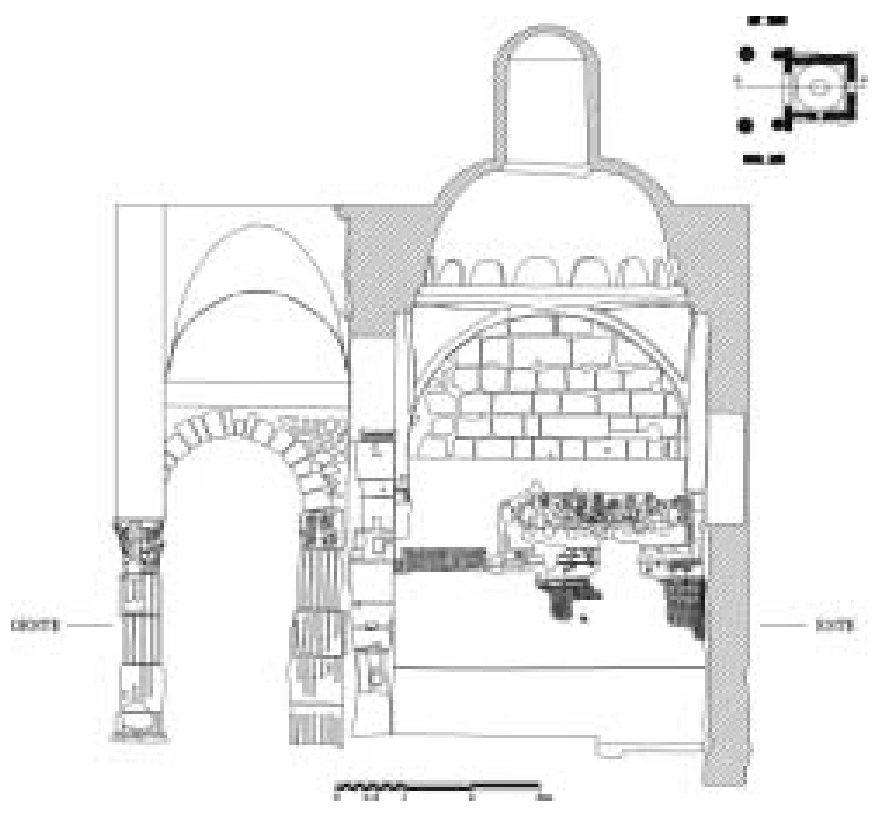

Fig. 3. Tricio: sección hacia el norte

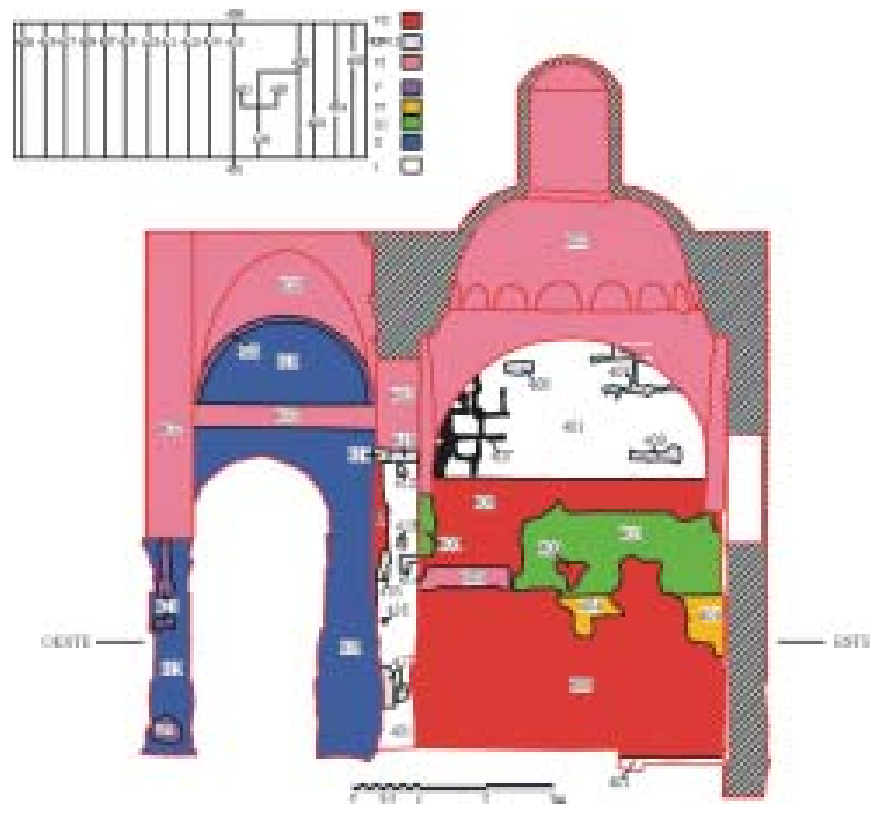

Fig. 4. Tricio: lectura de la sección hacia el norte tinto, mampostería de pequeñas lajas, que indica una renovación tecnológica respecto a las fases anteriores. En este momento se amortiza el ábside original, más pequeño que el actual y seguramente también cupulado con toba. ¿Cuánto tiempo ha transcurrido desde el primer al último edificio? Pensamos, en contra de la opinión de Aparicio, que la fase más antigua no puede fecharse a partir del hallazgo de un fragmento de sigillata datable en el vi ya que dicho fragmento forma parte de un relleno medieval, consecuencia de la reutilización de la tumba monumental ubicada a los pies de la nave de la que, arqueológicamente, sólo sabemos que puede ser coetánea a la primera iglesia. ¿Qué provocó las sucesivas reformas de la iglesia? ¿Son reparaciones de ruinas provocadas por abovedamientos mal planteados?

\section{REUTILIZACIÓN DE MATERIALES, NO DE EDIFICIOS}

El análisis de Tricio revela la existencia de una solución de continuidad constructiva entre el ábside y las naves que a todas luces nos habla de dos momentos edilicios diferentes (figuras 3 y 4). El primero, relativo al ábside, es de sillería romana reutilizada bien cortada y aparejada. El espacio se cubre con una bóveda de pechinas en toba. El segundo momento supuso la amortización de un aula previa y su sustitución por una estructura basilical de tres naves separadas por arquerías. El material edilicio sigue siendo de segunda mano - no perderse el detalle de los soportes de las arquerías a base de unos colosales tambores y capiteles romanos- si bien hay diferencias técnicas que dan como resultado un aparejo de pequeño tamaño e irregular disposición. Restos de un edificio romano, en pie, no hay por ningún lado frente a lo defendido por Andrés. El ábside, supuesto antiguo mausoleo reconvertido, es con total seguridad el presbiterio de una iglesia sin que exista el menor atisbo estratigráfico o tipológico que pueda decir lo contrario.

Santa Coloma, a falta de una lectura que incorpore la información sacada a la luz por las recientes intervenciones restauradoras, presenta, por el contrario, una unidad constructiva entre sus diferentes partes: el cuerpo central de dos alturas y los ábsides (figura 5). De nuevo tenemos que hablar de sillares romanos reciclados y estructuras con soluciones cupuladas semiesféricas sobre pechinas. Como en Tricio, se puede negar categóricamente que existan fábricas romanas en alzado reacondiconadas al culto cristiano. Cuerpo central y ábsides son coetáneos y espacios integrantes de un establecimiento religioso.

\section{SINGULARIDAD DECORATIVA}

Cada una de estas iglesias cuenta con elementos decorativos singulares dignos de reseñar. Tricio tiene en su ábside un 


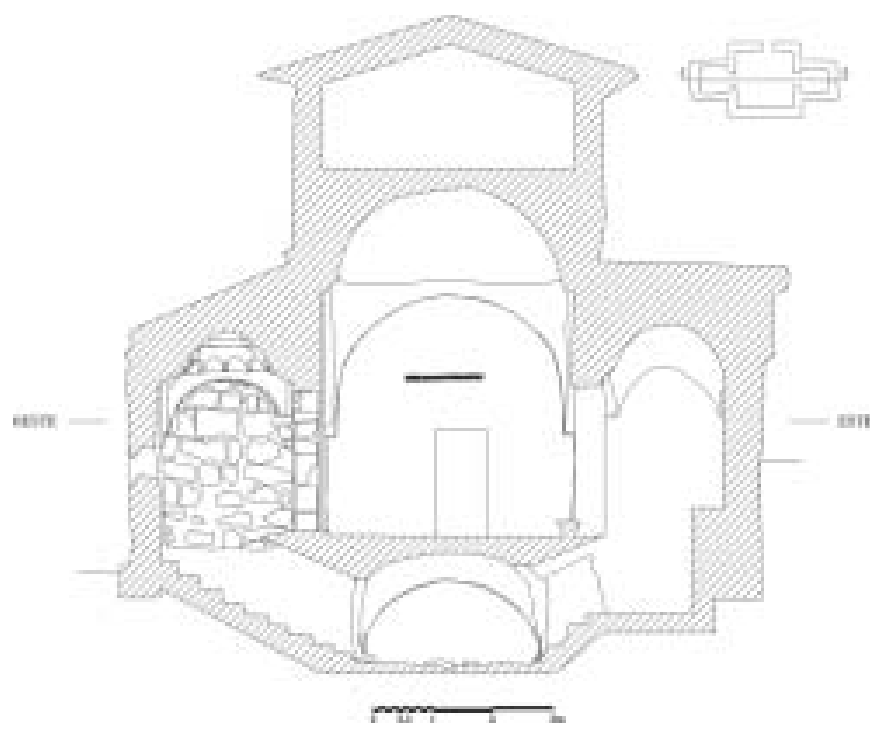

Fig. 5. Santa Coloma: sección hacia el norte

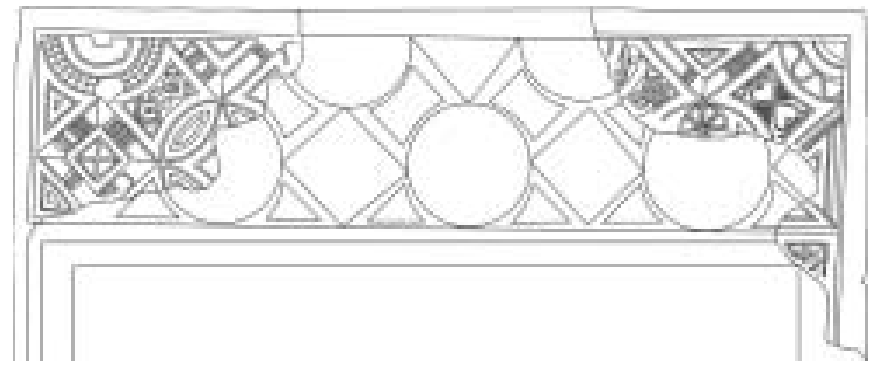

Fig. 6. Tricio: mosaico del ábside
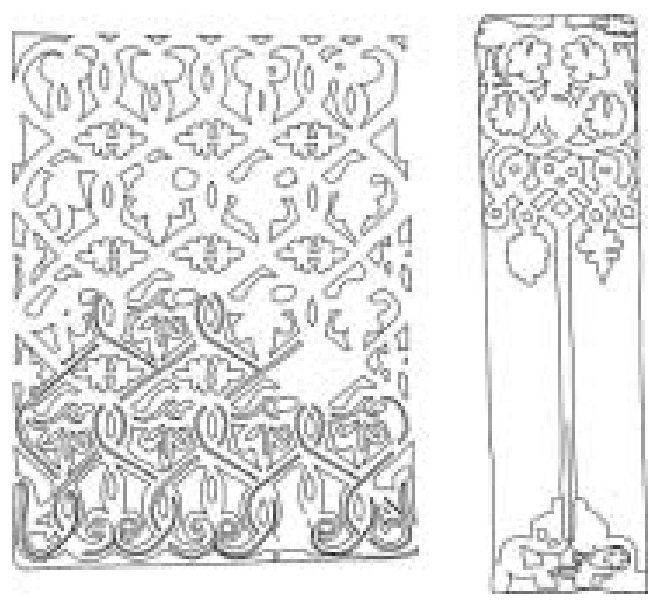

Fig. 7. Santa Coloma: placas de estuco mosaico (figura 6) coetáneo a la primera iglesia que, tal como se ha dicho, nada tiene que ver con un mausoleo romano. Esto implica reconocer la existencia de otro ejemplo de mosaico altomedieval, hasta ahora con un solo caso en el mausoleo de Santiago de Compostela (finales del s. IX). En Santa Coloma subsiste parte de la decoración parietal del estuco (figura 7), con paralelos formales y técnicos andalusíes. Por último, asociada a la tercera etapa altomedieval, en San Vicente del Valle encontramos una serie de capiteles con más vinculaciones con el sur de Francia que con cualquiera de las producciones peninsulares entre los siglos VII yx.

\section{PERVIVENCIA SECULAR O ADSCRIPCIÓN AL PERÍODO ALTOMEDIEVAL}

Tal como se decía más arriba, el análisis arqueológico paramental no es suficiente para dar una respuesta unívoca de carácter cronológico capaz de despejar las dudas que rodean al grupo arquitectónico del que hemos estudiado algunos ejemplos. Basándonos en nuestra experiencia al trabajar sobre estos objetos llegamos a la conclusión de que fueron producidos en un horizonte cultural y cronológico en el que unas mismas formas de trabajar y la vigencia de ciertas técnicas constructivas dieron resultados equivalentes. La cuestión estriba en saber, a tenor de la disparidad de fechas propuestas, si ese universo productivo y tecnológico estuvo vigente a lo largo de varios siglos o bien se concentra en un periodo más concreto. Nosotros nos inclinamos por la segunda posibilidad. Parece poco probable que durante 300 o más años se haya producido una inmutabilidad en la forma de materializar la arquitectura monumental. Entre otras cosas porque durante ese tiempo ocurren muchas cosas (reino visigodo, conquista musulmana, repoblación) que no hablan de un clima de estabilidad que justifique una pretendida invariabilidad del fenómeno material. Tampoco nos parece plausible una secuencia de creación-abandono-recreación en la línea de explicaciones de corte continuista que apelan al renacimiento de las fórmulas artísticas visigodas a partir del siglo IX. Sería el único caso de renacimiento artístico de la historia en el que no hay forma de distinguir los objetos originales de sus imitaciones a causa de la total y absoluta sintonía de los medios empleados y los resultados obtenidos. Por estas razones nos inclinamos a considerar esta familia arquitectónica como un grupo histórico y productivo homogéneo que sólo se pudo dar o bien en el periodo visigodo (siglo VII para ser más precisos) o bien en los primeros siglos de lo que antes se llamaba reconquista y ahora repoblación (siglos IX-X). Nunca con ejemplos en uno y otro momento. Esto quiere decir que los resultados de los casos concretos sirven de in- 
dicadores para aclarar la cronología del conjunto y, hoy por hoy, el único que aporta datos relacionables con cronologías precisas (San Román de Tobillas) se mueve en el siglo IX. Esto, desde luego, no zanja ni mucho menos la cuestión ya que todavía son muchos lo problemas e incertidumbres que rodean el estudio de la cultura material desde el siglo VII al X.

\section{Bibliografia}

Andrés Valero S., 1982, Excavaciones en Santa María de los Arcos, Tricio (La Rioja), I Coloquio sobre Historia de La Rioja, Logroño.

APARICIO J. A. y DE LA FuENTE A., 1986, Estudio arqueológico e intervención arquitectónica en la iglesia de la Asunción, San Vicente del Valle, Numantia, 6, pp. 153-171.

ArCe F. y CABAllero L., (en prensa), Análisis arqueológico de la arquitectura en la iglesia de la Asunción, San Vicente del Valle (Burgos), I Congreso de Arqueología de Burgos.

AZKARATE A., 1996, Aportaciones al debate sobre la arquitectura prerrománica peninsular: la iglesia de San Román de Tobillas (Álava), Archivo Español de Arqueología, 68, pp. 189-214.

HERAS y NÚÑEZ M.a A. DE LAS, 1986, Estructuras arquitectónicas riojanas. Siglos X-XII, Logroño.

Uranga J. E. e ÍNIGGUEZ F., 1971, Arte medieval navarro, vol. I, Pamplona. 